\title{
A Study of Day of the Week Effect in Karachi Stock Exchange During Different Political Regimes in Pakistan
}

\author{
Syed Muhammad Majid Shah ${ }^{1}$, Fahad Abdullah ${ }^{2}$
}

\begin{abstract}
In this study we attempt to examine the existence of day of the week effect in Karachi Stock Exchange during the three prominent political regimes of PML-N, PPP, and PML-Q, in context of Pakistan using six sub-samples (three on basis of changing trading days, and three on basis of changing political regimes) extracted from the KSE-100 index which is the benchmark of Pakistan's equity market and is the biggest and most dynamic operational stock exchange of Pakistan having a share of about 70 percent of total stock transition. Dummy variable approach is utilized in this study to uncover the day of the week effect in trading days during the sub-samples. The study finds evidence of existence of significant day of the week effect during the PPP regime with pronounced negative first trading day returns, while no significant negative returns are discovered during the PML-N and PML-Q regimes.
\end{abstract}

\section{Introduction}

A sizable amount of studies has been carried out in recent years which empirically test and document that relative returns of stocks are different on different week days. The most notable of these day of the week effects is a negative stock return on Mondays. These anomalies are also termed as calendar anomalies. These anomalies are observations which have been obtained by studies whose results are not consistent with the existing concepts of asset pricing models (Mazal, 2009). For the last seven decades, cyclical patterns, which are present in the behavior of various security prices, have been researched exhaustively and this area has now become a well-recognized arena for researchers. These seasonal patterns are more precisely termed as calendar effects and present an opportunity to be studied not only by social scientists, but also by the stock and financial market players (Bespalko, 2009).

Abnormally spiked or plummeting average stock returns which rely on calendar dates are termed as calendar anomalies or calendar effects on the stock returns because the behavior of stock markets depend chiefly on specified durations occurring in a year. The Halloween effect, day of the week effect, January effect, and the turn of the month effect are four prominent anomalies which have been thoroughly discussed

1 Quaid-e-Azam College of Commerce, University of Peshawar, Pakistan

2 Assistant Professor, Institute of Management Sciences, Peshawar. 
and empirically studied as well.

One of the most interesting as well as intriguing topics in finance is seasonality or calendar anomaly which has been extensively studied during the last three decades. Ramzan effect, Week effect, day of the week effect, month effect, and January effect etc. are some of these stock price irregularities. Day of the week effect is one such anomaly which has been studied the most by researchers from different parts of the globe. The day of the week effect means that that the average returns of stocks are distributed in an uneven manner among the different days of the week (Haroon \& Shah, 2013). Whereas the Efficient Market Hypothesis postulates that prices of stock as well as their average returns should be normally distributed. However, in contrast, the empirical evidence from numerous studies indicates the presence of the inherent seasonal anomalies resulting in inconsistent stock yields.

The Efficient Market Hypothesis postulates that the prices of financial assets traded on markets are fully inclusive of the available information which play a chief role in their determination. Resultantly, the market takes the form of an efficient market and therefore lacks any investment opportunity which can be exploited by investors to generate above average or high returns. These high returns represent differences present between the expected returns and the actual returns gained on the financial assets (Gugten, 2010). The concept of Efficient Markets assumes that these effects are likely to vanish once they have been explored by researchers and undertood by the security traders. However, these anomalies continue to exist for quite a long time which is itself an abnormality. They include month of the year, day of the month and day of the week effects (Bespalko, 2009). Researchers like Polwitoon and Tawatnuntachai (2008) have indicated the presence of these anomalies, while Nippani and Arize (2007) have presented that some of these anomalies are vanishing in the developed markets.

The theory of Efficient Market Hypothesis (EMH) was proposed by Fama in which he claims that financial markets are exceptionally capable of reflecting complete stock price information. This implies that the current price already reflects all known information about the stock and that it will not be possible to earn excess returns from the market. The EMH is associated with the idea of a "random walk," which is a term lightly used in the literature to illustrate the series of prices where all the succeeding changes in stock prices represent arbitrary differences from the previous stock prices (Malkiel, 2003). It is therefore depicted that the information flows without any hindrance and is immediately reflected in stock prices.

Eugene Fama, a pioneer in efficient markets research, has described three levels of market efficiency: 
- Weak-form efficiency: Current prices fully reflect the historical sequence of prices. In short, knowing past price patterns will not help you improve your forecast of future prices.

- Semistrong-form efficiency: Current prices fully reflect all publicly available information, including such things as annual reports and news items.

- Strong-form efficiency: Current prices fully reflect all information, both public and private (i.e., information known only to insiders) (Van Horne \& Wachowicz, $\mathrm{Jr}, 2008)$

Three stock exchanges are presently operational in Pakistan viz. Islamabad Stock Exchange (ISE), Lahore Stock Exchange (LSE) and the Karachi Stock Exchange (KSE). However, this study is undertaken for the purpose of examining the existence of Day of the Week Effect exclusively in the Karachi Stock Exchange of Pakistan during three different political regimes of Pakistan Muslim League-N (PML-N), Pakistan Peoples' Party (PPP), and Pakistan Muslim League-Q (PML-Q) after the economic reforms of 1991.

During the post-liberalization stage of the KSE, numerous researchers including Hussain and Qasim (1997), Hussain (1998), Hussain (2000), Hussain, Hamid, Akash, and Khan (2011), and Haroon and Shah (2013) have tried to find whether it is operatingly efficiently or otherwise. If the market is inefficient, anomalies are found which can aid investors in gaining unusually high stock returns by performing preset and calculated tactics inside the market (Guo \& Wang, 2007). Such anomalies present in the financial market deny the efficient market hypothesis (EMH). This paper studies day of the week effect during prominent political regimes in Pakistan to discover the existence of varying return patterns during week days.

This paper is important in a twofold manner. First, as far as review of relevant literature in this area is concerned, this is an effort to analyze the day of the week effect during different political regimes in context of the Pakistani financial markets, which adds to the existing literature. Second, it benefits the decision making and increases the knowledge base of the practitioners, i.e. market investors as well as academicians. The Practitioners can take guidance from this study in their investment decisions and can potentially take better decisions, while the academicians will be in a position to get guidance and assistance in theory development and research activities. Along with individual investors, Institutional investors, mutual funds and the like will be equally in a better position to utilize the findings of this paper to aid them in sound decision making. These analyses can provide important information regarding the rationality of justifications already provided for the Day of the Week effect. 


\section{Literature Review}

The DOTW effect is a topic which has attracted a lot of attention from researchers for decades. Most commonly researched among these is the Monday effect, which implies that the mean stock returns on Mondays are much lesser than returns on the other working days of the week while the highest average stock returns are normally discovered on Fridays over majority of the global financial markets (Mitra \& Khan, 2014). However, some empirical studies conducted in different international stock markets have also reported that stock returns exhibit abnormal behavior on third trading day i.e Tuesday instead of the more common Monday effect (Guo and Wang, 2007)

Numerous researchers have studied the relationship between political administrations and the macroeconomic variables. Accordingly, relationships of different natures have been identified by researchers such as Neiderhoffer, Gibbs, and Jim (1970), Allvine and O'Neill (1980), Riley and Luksetich (1980), Chappell and Keech (1986), Alesina and Sachs (1988), Hensel and Ziemba (1995) and Liano, Liano, and Manakyan (1999). Chappell and Keech (1986) have identified growth in the Gross National Product in the first half term of the Democratic Administration as compared to the second half term of the Republican Administration. Siegel (1994) in his detailed study of over a century of Dow Jones Industrial Average (DJIA) stock returns has found out that the stock market has shown an increasing trend on the next day of Republican wins and has shown a decreasing trend on the next day of Democratic wins. Same results have been posted by Neiderhoffer et al. (1970) and Riley and Luksetich (1980). Allvine and O'Neill (1980) have concluded that stock returns tend to move higher in the last two years of the Presidential term period as compared to the first two years. Huang (1985) puts forth the same conclusion. In contrast, Kansas (1996) reports that the market returns are lower in the fourth year of Republican Presidents (11.1\%) as compared to a 15 percent stock yield in the $4^{\text {th }}$ year of Democrats. Liano et al. (1999) in their study have found that negative returns on Mondays are more apparent and strong during the Administration of Republicans as compared to the Democratic Administrations. These studies make the fact quite evident that stock returns are influenced by change in governments.

Despite the presence of the EMH, there still exists a sizable amount of work on the day of the week effect of stock market yield/return. When the mean stock returns on Monday is significantly lower than the mean stock returns for the other days, day of the week effect is said to exist. The generally utilized method to this problem is by using the dummy variable method which is based on a linear regression with 5 dummy variables each representing the respective days of the week.

Seasonality has been studied by different researchers who have observed the 
evidence of abnormal return spread based upon the day of the week. Data from the U.S. market was utilized for the first time by researchers while attempting to uncover the seasonality in returns. Cross (1973) observed positive returns on Fridays while negative returns on Mondays in the Standard \& Poor's Composite Stock Index. French (1980) observed negative mean share returns for Mondays from 1953 to 1977 on the New York Stock Exchange. Similarly Gibbons and Hess (1981) have given proof of negative returns on Mondays. Lakonishok and Levi (1982) put forward that the daily returns should depend on the day of the week, however they do propose an adjustment to be made for interest gains on certain days over adjacent business days. Keim and Stambaugh (1984) find consistently negative Monday returns for the Standard \& Poor Composite Index as early as 1928.

This effect has also been analyzed in security markets internationally by Jaffe and Westerfield (1985) who examined the daily stock market returns for four foreign countries and discovered weekend effect in each country. Chang, Pinegar, and Ravichandran (1993) presented mixed results for seven European Countries, Canada, and Hong Kong. Dubois and Louvet (1996) examined the stocks of nine countries during the 1969-1992 period and reported lower returns at the start of the week.

Berument and Kiymaz (2001) have confirmed the existence of day of the week effect both in stock market volatility and returns. They find highest stock returns on Wednesday and lowest stock returns on Monday. Furthermore, the highest stock return volatility is observed on Friday while Wednesday shows the lowest volatility. Chang et al. (1993) in their research on the international markets have reported significant Monday returns in 13 out of 23 international economies. Chen, Kwork, and Rui (2001) report negative returns on Tuesday which they attribute to information spillover from America to Europe and then Asia. They also declare that the day of the week anomaly is dependent on their estimation method and the sample period. Chia, Liew, Wafa, and Wafa (2006) have examined overall calendar anomalies in the Malaysian stock market and negative Monday returns period have been discovered. Demirer and Karan (2002) in their study of the Istanbul Stock Exchange-ISE document that the stock returns on Friday normally remain high. However no Monday or Tuesday effect has been found. However, Dicle and Hassan (2006), in their study on the Istanbul Stock Exchange indices declare statistically significant weekdays effect for Mondays (with negative returns), for Thursdays (with positive returns) and for Fridays (with positive returns).

Hussain (2000) in his study of the Karachi Stock Exchange indicates a presence of the week day effect in the market with the lowest stock returns on the first trading day, i.e. Saturday. However, after the opening of the market to international investors, this anomaly tends to fade away. Similarly, Hussain et al. (2011) have examined the 
daily returns for KSE and have uncovered a significant Tuesday effect. Ke, Chiang, and Liao (2007) in their paper have discovered a persistent day of week effect in the foreign exchange market of Taiwan in recent years. They attribute it to the immaturity or inefficiency of the Taiwan foreign exchange market. Kiymaz and Berument (2003) in their study indicate the presence of the day effect. Their findings show that the highest return in on Wednesday, whereas the lowermost stock return is discovered on Mondays. Liano and Gup (1989) have analyzed the S\&P Composite Stock Index by utilizing two distinct stock return indices in times of Economic Expansions and Contractions. During Expansions, on Mondays, returns were negative while positive on Wednesday, Thursday and Friday.

Lakonishok and Smidt (1988) in their overview of 90-year period of Dow Jones Industrial Average (DJIA) have discovered a consistently recurrent seasonal anomalies such as the Day, Week, Month, Year and Holiday effects. According to their findings, Monday shows negative returns throughout the history. Lakonishok and Levi (1982) have presented their conclusion that the stock returns 'should' depend on the weekdays and that adjustment in the interest gains on business days should be made to reflect factual figures. Cross (1973) has examined the distribution of price changes on Fridays and Mondays and the existing relationship between the two and has found out that the association among the security price fluctuations on Friday and that of Monday is considerably dissimilar as compared to the relationship between security price fluctuations on other succeeding trading days.

Ajayi, Mehdian, and Perry (2004) in their study on the Eastern European Emerging Markets (EEEM's) found that there are negative as well as positive Monday returns in the eleven EEEM's but only three out of these eleven findings are statistically significant; which is not sufficient to support the existence of any significant daily patterns in the stock market returns of the EEEM's. Abdallah (2012) in an attempt to find day of the week effect on stock returns and the conditional volatility of the Khartoum Stock Exchange (KSE) from Sudan did not document any day of the week effect in his findings. Similarly, Apolinario, Santana and Sales (2006) in their paper study the day of the week effect in different European stock markets along with volatility of these markets and concluded that most of the European markets do not reflect a day of the week effect.

Demirer and Karan (2002) in their paper have presented a comprehensive summary of seminal literature work on Day of the Week Effect in Stock Markets Worldwide wherein they state that Cross (1973), French (1980) finds negative stock returns on Mondays in the Standar \& Poor 500 Index. Gibbons and Hess (1981) disclose Negative Monday returns in the DJIA. Keim and Stambaugh (1984) discover that on S\&P 500 Index there are negative Monday returns along with a Positive correlation between 
the returns on Fridays and Mondays. Rogalski (1984) has reported weekend anomaly in the months of December, January and February. Jaffe and Westerfield (1985a), in their study of Japanese and Australian markets have documented Negative mean returns on Tuesday. Smirlock and Starks (1986) disclose negative returns on Mondays on hourly basis, whereas positive hourly mean returns are disclosed in the afternoon on Mondays. Board and Sutcliffe (1988) find reversed weekend effect in the mean returns of British stock markets. Connolly (1989) states that the weekend effect in the stock returns of US markets tend to vanish after 1975. Solnik and Bousquet (1990) have disclosed a negative stock return on Tuesday while studying the CAC Index of Paris Bourse, and finally Barone (1990) in his study on the Milan Stock Exchange discovers Negative stock returns on Tuesday.

\section{Methodology}

This study takes into consideration the Pakistani equity market at different periods of time categorized into three prominent political regimes of Pakistan Muslim League Nawaz (PML-N), Pakistan Peoples' Party (PPP) and Pakistan Muslim League Quaid-eAzam (PML-Q). The historical stock returns of the (KSE) 100 Index Companies are used in line with Campbell et al (2012).

Sample period from $14^{\text {th }}$ December 1991 to $22^{\text {nd }}$ March 2013 has been selected for the purpose. The total observations for daily data have been divided into 6 Sub-samples including 3 periods of Pakistan Muslim League (N) PML-N, Pakistan Peoples' Party PPP and Pakistan Muslim League (Q) PML-Q administrations respectively as follows:

a. PML-N regime starting from November $6^{\text {th }}, 1990$ (Taken from December 14, 1991 due to non-availability of data and change of trading days on this date) to April $18^{\text {th }}, 1993$ and February $17^{\text {th }}, 1997$ to October $12^{\text {th }}, 1999$

b. PPP regime from October $19^{\text {th }}, 1993$ to November $5^{\text {th }}, 1996$ and February $18^{\text {th }}$, 2008 to February $18^{\text {th }}, 2013$

c. PML-Q regime from May $12^{\text {th }}, 1999$ to August $18^{\text {th }}, 2008$

3 subsamples on the basis of changing stock trading days throughout the course of study:

a. From December 14, 1991 to June 06, 1992 the trading days were Saturday to Wednesday

b. From June 07, 1992 to February 27, 1997 the trading days were Sunday to Thursday 
c. From February28, 1997 to Feb 18,2013 the trading days were Monday to Friday

Trading days were treated as sequence of the days, that is, first day of trading (Day1), third day of trading (Day3), etc. Labels of the days i.e. Monday, Tuesday, etc. were ignored during the process (Nishat \& Mustafa, 2002). Thus quantitative method has been used in the study.

\subsection{Hypotheses}

$\mathrm{H}_{\mathrm{o}}=$ Daily log return of a specific trading day equals the daily log return of the other trading days

$\mathrm{H}_{1}=$ Daily $\log$ return of a specific trading day does not equal the daily log return of other trading days

\subsection{Removing Non-Stationarity}

The data utilized to incorporate the dummy variable models comprises of the daily trading data of KSE-100 index which is a time-series data and henceforth incorporates the problem of non-stationarity which needs to be promptly addressed. One of the widely used measures of transforming non-stationary stock returns time series data into stationary data is by taking the average daily returns which have been found out using log of the quotient of closing and opening values to make the data stationary and usable. This is because the stock prices are constantly changing whereas the returns on stock exhibit a stable pattern. Therefore the returns present a more acceptable and applicable scenario for study and the outcomes of investigating stock returns is of great significance for the investors. The return values for each index have been calculated as the log of difference of two successive prices according to this widely used approach $r_{t}=\ln \left(v_{t} / v_{t-1}\right)$, where " $r_{t}$ " is the return in the period $t, " v_{t}$ " is the daily closing share price index at a particular time $t$, " $v_{t-1}$ " is the daily closing share price index for the preceding period and "ln" is the natural logarithm.

\subsection{Dummy Variable Approach}

Dummy Variable models are used to analyze the seasonal behavior of stock market and utilize a simple regression model, in which the excess return for a specific trading day is denoted by a unique dummy variable. However, it is not possible to estimate this model if it the dummy variables are all present along with the constant term. It will result in the problem of perfect multicolinearity. A great majority of researchers eliminate either one of the dummy variables or the constant term from the regression equation to cope with this problem. However, regressing the dependent variable on the independent dummy variables in this way removes the perfect multicolinearity. 


\subsection{Model of the Study}

This study utilizes OLS Regressions with Dummy variables (to represent Days of the Weeks) in order to check the DOTW effect during PML-N, PPP and PML-Q regimes as well as during the other three sub-samples on the basis of changing trading days.

As simple linear regression models are classic and commonly used mostly by researchers of seasonal calendar anomalies in the financial markets therefore the following model is suggested in this study:

$$
\operatorname{Ret}_{t}=\alpha 1+\alpha_{2} D_{2} t+\alpha_{3} D_{3} t+\alpha_{4} D_{4} t+\alpha_{5} D_{5} t+\varepsilon_{t}
$$

This model has been utilized for the full time period and each of the three sub-samples on the basis of changing trading days, in order to evaluate the relationship between Returns and the respective days of the week.

$$
\operatorname{Ret}_{i t}=\alpha_{1 i}+\alpha_{2 i} D_{2 t}+\alpha_{3 i} D_{3 t}+\alpha_{4 i} D_{4 t}+\alpha_{5 i} D_{5 t}+\varepsilon_{i t}
$$

Where,

$$
\begin{aligned}
& \operatorname{Ret}_{i t}=\text { KSE returns during } i \text { admin on day } t \\
& i=1 \text { for PML-N, } i=2 \text { for PPP and } i=3 \text { for PML-Q }
\end{aligned}
$$

This model has been utilized for the full sample period and each of the three sub-samples of political regimes in order to evaluate the relationship between Returns and the respective days of the week during political regimes.

Further, as discussed in the previous sections, many researchers have utilized the models of volatility in their respective studies, However, the purspose of applying such models is to address the problem of risk and or volatility in the stock market returns. Since this is not amongst the objectives to find out the risk or volatility in KSE - 100, therefore such modelling has not been made in this study.

\subsection{Variables}

The variables utilized in the model comprise of the dependent variable of KSE Stock returns denoted by on any given day t. are dummies for the respective days of the week and assume the value of 1 if the stock returns on Day $t$ fall on second trading day to fifth trading day, and 0 Otherwise. is a vector of the residual terms also called the error term of the model or simply the residual. is the intercept term which measures average daily returns on first trading day of the week while are coefficients that provide a pair-wise evaluation inbetween mean daily returns on first trading and 
the mean daily returns on second trading day to fifth trading day of week.

However, literature suggests the possibility of existence of heteroscedasticity and autocorrelation in the time-series data. For instance as (Akgiray, 1989) indicates, "the presence of linear dependence in daily return series of market indices can be attributed to various market phenomena and anomalies. The presence of a common market factor, the problem of thin trading in some stocks, the speed of information processing by market participants and day of the week effects could contribute partially to the observed first order autocorrelations". Therefore the use of corrective measures to avoid the issues of heteroscedasticity and autocorrelation becomes necessary during the estimation process.

This study uses the correction technique proposed by (Newey \& West, 1987) for the correction of heteroscedasticity and autocorrelation which is a methodology to compute heteroskedasticity and autocorrelation-consistent (HAC) standard errors. Therefore these HAC standard errors are also termed as Newey-West standard errors. This technique is associated with the correction technique of heteroscedasticity proposed by (White, 1980) which utilizes White standard errors. However the Newey-West standard errors must be calculated by selection of maximum lag. Since the Newey-West method comprises of an expression in the squares of the residuals which is identical to White's formula (as well as a second term in the cross-products of the residuals), these robust estimates incorporate White's correction. Newey-West standard errors in a time series context are robust to both arbitrary autocorrelation (upto the order of the chosen lag) as well as arbitrary heteroscedasticity (Wooldridge, 2006).

\section{Results and Discussion}

Results of this study are reported in tabulated form while incorporating the statistical tools of mean, standard deviation and t-test. Mean measures the central tendency of the sample of study under observation and has been reported as percentages while function of standard deviation in statistical studies is mainly to evaluate the statistical dispersion of the sample data around the mean. It can also be utilized as a measure of risk. While the t-test helps to check that if the average of two normally distributed study populations are equal or not. This analysis will help in answering the main theme of the study i.e. is the day of the week effect present in the KSE throughout the different political regimes?

Figure 1 depicts that the first trading day has the lowest negative mean return which is followed by second trading day. The highest positive mean return can be observed on the third trading day which is followed by the fifth day. The fourth trading day depicts positive but comparatively low mean returns. The highest positive return 


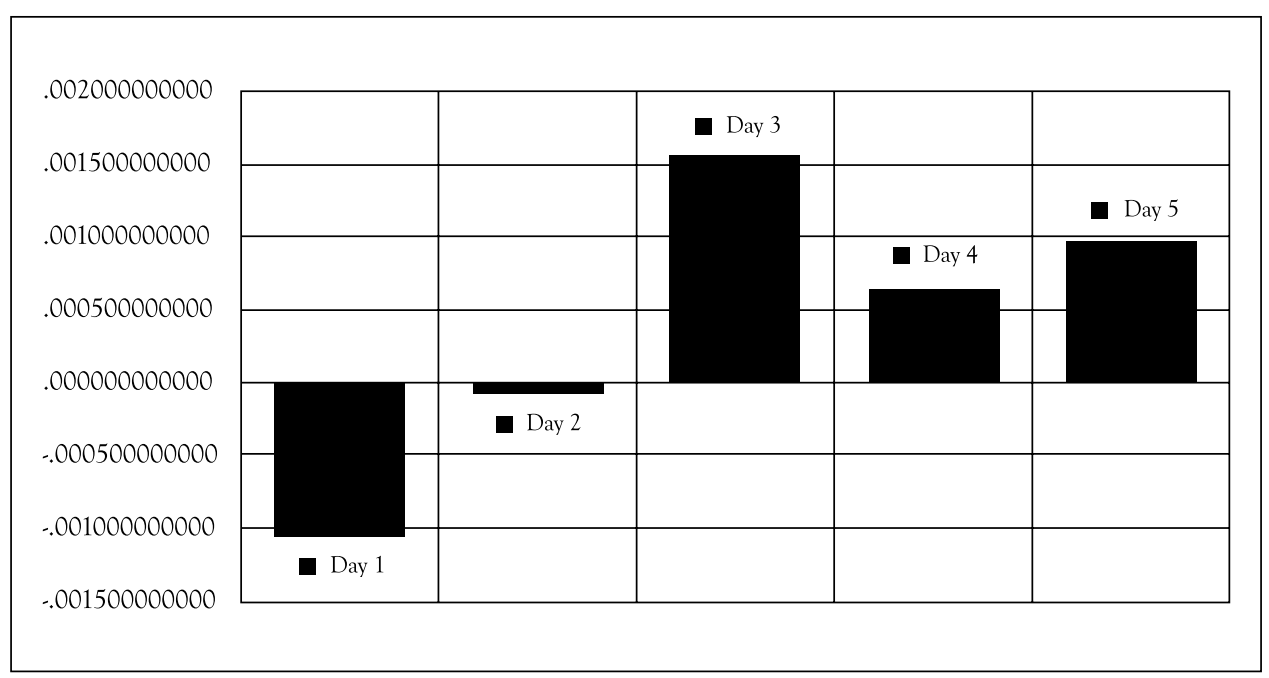

Figure 1: Mean Returns for Full Sample

on third trading day can be possibly interpreted as an explanation of an inherent DOTW effect existent in the full sample of this study.

Table 1: Mean Stock Returns by Day of the Week for the full sample

\begin{tabular}{|c|c|c|c|c|c|c|}
\hline $\begin{array}{c}\text { Summary } \\
\text { Statistics }\end{array}$ & 1st Day & 2nd Day & 3rd Day & 4th Day & 5th Day & Cumulative \\
\hline Obs (n) & 997 & 999 & 1016 & 1008 & 973 & 4993 \\
\hline MinVal & -0.1321329 & -0.091453 & -0.0678251 & -0.0764485 & -0.0890789 & -0.1321329 \\
\hline MaxVal & 0.074849 & 0.100029 & 0.1276223 & 0.0716412 & 0.0850712 & 0.1276223 \\
\hline Mean & -0.0010676 & -0.0000852 & 0.0015671 & 0.0006578 & 0.0009798 & 0.0004124 \\
\hline t-stat & $-3.227^{*}$ & -1.295 & $2.952^{*}$ & 0.684 & 1.472 & - \\
\hline Df & 996 & 998 & 1015 & 1007 & 972 & - \\
\hline p-value & 0.001 & 0.195 & 0.003 & 0.494 & 0.141 & - \\
\hline
\end{tabular}

Level of Significance/Decision Rule $(\alpha)=0.05$

Table 1 reports the summary statistics of all trading days of the full sample of study. The summary statistics include the number of observations of day under observation, the minimum and maximum values of the Daily KSE Returns throughout the period under observation, the mean KSE Returns for each particular day, the degrees of freedom for the t-test conducted and finally the probability value for the t-test conducted. (The preceding paragraph is applicable to Tables from 1 to 7 )

The mean daily KSE Returns for the full sample have been discussed in light of Figure 1 in the paragraph preceding Table 1 . The results of t-test are discussed below. 
Results of the t-test have been presented based on the hypothesis that daily log return of a specific trading day equals the daily log return of the other trading days $\left(H_{o}: \mu 1=\mu 2\right)$. First trading day displays the lowest mean return, which is significant, at -0.0010676 and third trading day demonstrates the highest mean return, which is significant, at 0.0015671 as shown by their respective t-values. As evident from Table 1 , the p-value of the first day $(0.001)$ as well as the third Day (0.003) is less than the set value of 0.05 , so $\mathrm{H}_{\mathrm{o}}$ can be rejected, which points out that the average return on first day and third days are different in a significant manner from respective returns of the other days. Consequently, for the entire period of study there exists a negative first trading day effect and a positive third trading day effect, which is consistent with the findings of Berument and Kiymaz (2001) and Liano and Gup (1989). It implies that due to accumulation of information from last trading (closing) day to first trading (opening) day of the week, investors are reluctant to invest on the first day of the week.

Figure 2 shows that the second trading day has the lowest negative mean return which is followed by first, fifth and fourth trading days. The highest and the only positive mean return can be observed on the third trading day. Results of the t-test are presented in Table 2 .

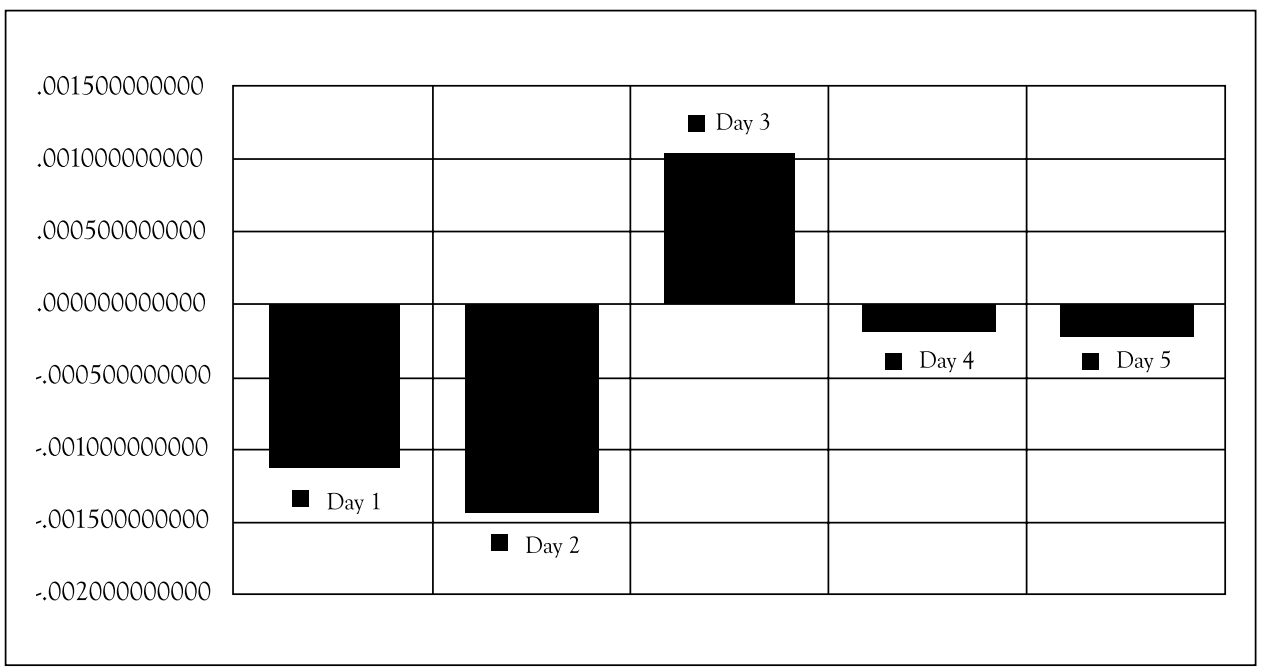

Figure 2: Mean Returns for PML-N Regime

While comparing with those of other trading days, the average returns of third trading day display the largest yet insignificant difference as evident from the $t$-value of 1.347. So based on its p-value of 0.179 which is larger than the threshold value, the hypothesis can not be rejected. This implies that the average stock returns between third day and the other trading days are not different statistically. As usual, the first trading day shows lowermost yield of -0.001127 , while its $p$-value of 0.534 greater than 
Table 2: Mean Stock Returns by Day of the Week for PML-N Regime

\begin{tabular}{|c|c|c|c|c|c|c|}
\hline $\begin{array}{c}\text { Summary } \\
\text { Statistics }\end{array}$ & 1st Day & 2nd Day & 3rd Day & 4th Day & 5th Day & Cumulative \\
\hline Obs (n) & 219 & 219 & 219 & 215 & 203 & 1075 \\
\hline MinVal & -0.132132 & -0.091453 & -0.067825 & -0.057633 & -0.089079 & -0.1321329 \\
\hline MaxVal & 0.074849 & 0.100029 & 0.1276223 & 0.0716412 & 0.0548612 & 0.1276223 \\
\hline Mean & -0.001127 & -0.001426 & 0.0010385 & -0.000181 & -0.000220 & -0.0003867 \\
\hline t-stat & -0.622 & -1.051 & 1.347 & 0.231 & 0.165 & - \\
\hline Df & 218 & 218 & 218 & 214 & 202 & - \\
\hline p-value & 0.534 & 0.295 & 0.179 & 0.817 & 0.869 & - \\
\hline
\end{tabular}

Level of Significance/Decision Rule $(\alpha)=0.05$

Obs (n): Number of observations. MinVal: Minimum Value of the Daily KSE Returns. MaxVal: Maximum Value of the Daily KSE Returns. Mean: Average of the Daily Returns. t-test: $\mathrm{H}_{\mathrm{o}}$ states that the average daily log return of the investigated day is equal to the average daily log return of other weekdays.

$\alpha=0.05$, showing that average returns of first trading day are not significantly different in comparison with other days, so there is no day effect on first trading day. In fact the p-values of t-test are found to be insignificant, which show that the difference in mean returns between any trading day under observation and other trading days proves to be insignificant for the PML-N Regime. This is consistent with Ajayi et al. (2004) and Apolinario et al. (2006). In a nutshell, the day of week effect does not display a significant presence during the PML-N Regime.

Figure 3 indicates lowest negative mean returns on the first trading day followed

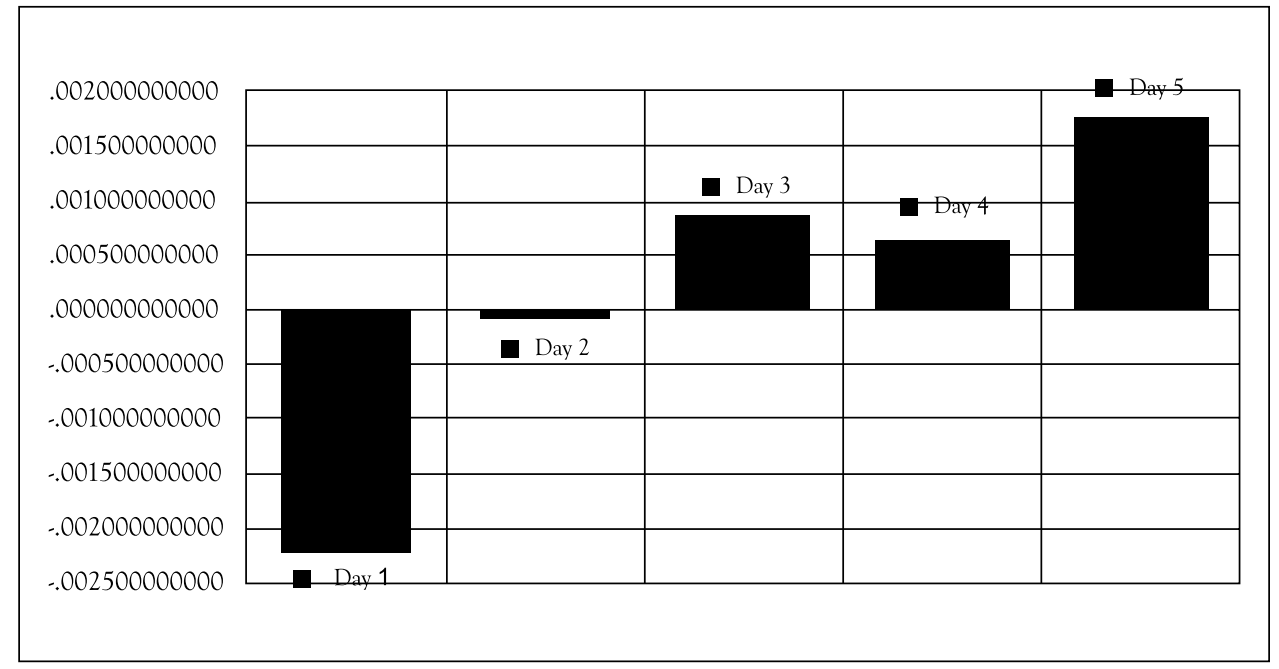

Figure 3: Mean Returns for PPP Regime 
by the second day. Highest positive mean returns are found on the fifth trading day which is followed by third and fourth trading days respectively. Results of the t-test are presented in Table 3.

Table 3: Mean Stock Returns by Day of the Week for PPP Regime

\begin{tabular}{|c|c|c|c|c|c|c|}
\hline $\begin{array}{c}\text { Summary } \\
\text { Statistics }\end{array}$ & 1st Day & 2nd Day & 3rd Day & 4th Day & 5th Day & Cumulative \\
\hline Obs (n) & 395 & 405 & 412 & 412 & 400 & 2024 \\
\hline MinVal & -0.055272 & -0.043131 & -0.051348 & -0.046082 & -0.047794 & -0.0552722 \\
\hline MaxVal & 0.05396 & 0.0825469 & 0.0477255 & 0.052932 & 0.0431577 & 0.0825469 \\
\hline Mean & -0.002230 & -0.000064 & 0.0008616 & 0.0006546 & 0.0017461 & 0.0002057 \\
\hline t-stat & $-4.179^{*}$ & -0.519 & 1.238 & 0.956 & $3.008^{*}$ & - \\
\hline Df & 394 & 404 & 411 & 411 & 399 & - \\
\hline p-value & 0.000 & 0.604 & 0.216 & 0.340 & 0.003 & - \\
\hline
\end{tabular}

Level of Significance/Decision Rule $(\alpha)=0.05$

Obs (n): Number of observations. MinVal: Minimum Value of the Daily KSE Returns. MaxVal: Maximum Value of the Daily KSE Returns. Mean: Average of the Daily Returns. t-test: $\mathrm{H}_{\mathrm{o}}$ states that the average daily log return of the investigated day is equal to the average daily log return of other weekdays.

First trading day shows significantly lower average yield at -0.002230 and fifth trading day displays a significantly high mean return at 0.0017461 as shown by their respective t-values. As evident from the above table, $\mathrm{p}$-values of the first day $(0.000)$ and third Day (0.003) are less than the threshold value of 0.05 , so $\mathrm{H}_{\mathrm{o}}$ can safely be overruled, which points out that the mean return on first day and fifth days are significantly different in comparison with other trading days. Consequently, the PPP Regime exhibits a negative first trading day effect and a positive fifth trading day effect, which is consistent with the already established western theoretical framework as thoroughly discussed in the literature review section.

Figure 4 indicates interesting results with all positive mean returns for the PML-Q Regime with the highest positive mean return on the third day followed by fourth, fifth, second and first trading days respectively. Results of the t-test are presented in Table 4.

The third trading day shows a significantly highest mean return at 0.0026332 as depicted by its t-value of 2.591. The corresponding p-value of 0.010 is lesser than the threshold of 0.05 which indicates that the null hypothesis can be rejected in favor of the fact that the mean returns of this particular day (third trading day) are different from those of the other weekdays. This is consistent with the findings of Ross, Westerfield, and Jaffe (2002) and Kiymaz \& Berument (2003). On the basis of these findings, the study can propose that Wednesday effect prevailed in the PML-Q 


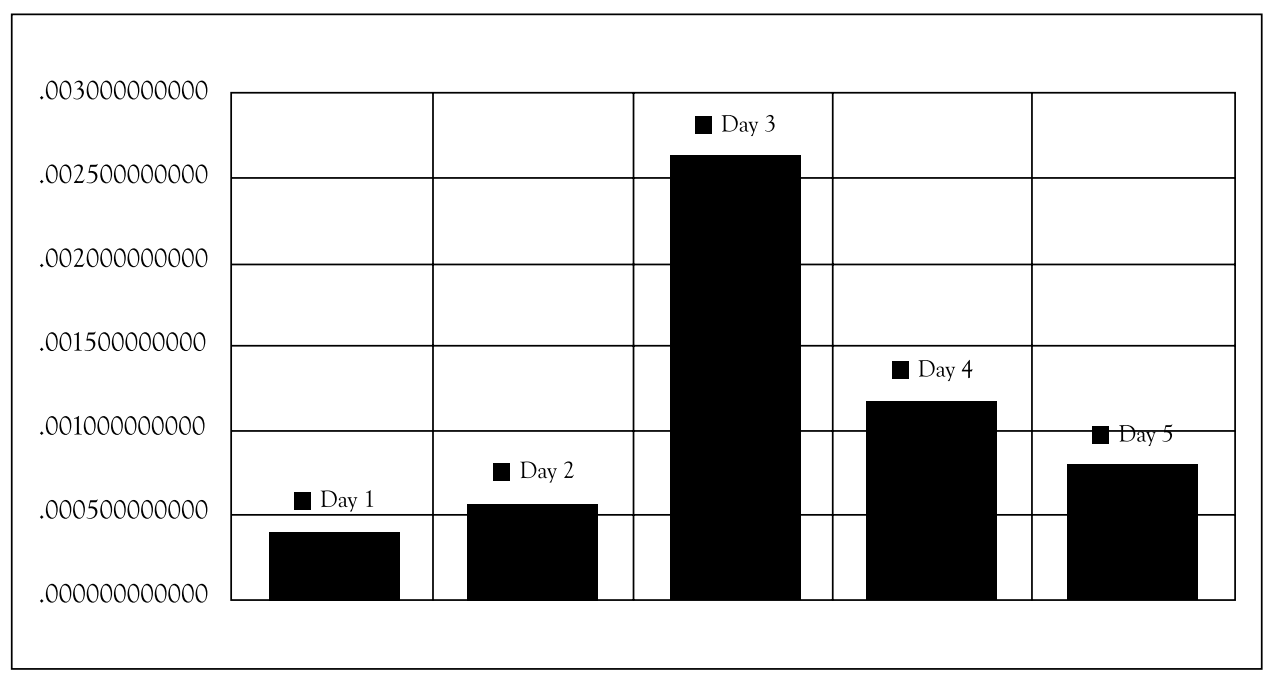

Figure 4: Mean Returns for PML-Q Regime

Regime. Rest of the mean returns of first, second, fourth and fifth trading days are not significantly different as evident from their $p$-values which indicates that their mean returns are not depicting any day of the week effect.

Table 4: Mean Stock Returns by Day of the Week for PML-Q Regime

\begin{tabular}{|c|c|c|c|c|c|c|}
\hline $\begin{array}{c}\text { Summary } \\
\text { Statistics }\end{array}$ & 1st Day & 2nd Day & 3rd Day & 4th Day & 5th Day & Cumulative \\
\hline Obs (n) & 413 & 405 & 414 & 408 & 400 & 2040 \\
\hline MinVal & -0.077413 & -0.070015 & -0.060417 & -0.076448 & -0.065876 & -0.0774138 \\
\hline MaxVal & 0.0644941 & 0.0620642 & 0.0726624 & 0.0726624 & 0.0850712 & 0.0850712 \\
\hline Mean & 0.0004085 & 0.0005739 & 0.0026332 & 0.0011791 & 0.0007907 & 0.0011219 \\
\hline t-stat & -0.970 & -0.920 & $2.591^{*}$ & 0.096 & -0.544 & - \\
\hline Df & 412 & 404 & 413 & 407 & 399 & - \\
\hline p-value & 0.333 & 0.358 & 0.010 & 0.923 & 0.587 & - \\
\hline
\end{tabular}

Level of Significance/Decision Rule $(\alpha)=0.05$

Obs (n): Number of observations. MinVal: Minimum Value of the Daily KSE Returns. MaxVal: Maximum Value of the Daily KSE Returns. Mean: Average of the Daily Returns. t-test: $\mathrm{H}_{\mathrm{o}}$ states that the average daily log return of the investigated day is equal to the average daily log return of other weekdays.

Figure 5 reports the mean returns for sample in which trading days were from Saturday to Wednesday. As is evident, the second trading day has the lowest mean returns which are followed by the third, first and the fifth trading day. The only positive mean returns are present on the fourth trading day. Results of the t-test are presented in Table 5 . 


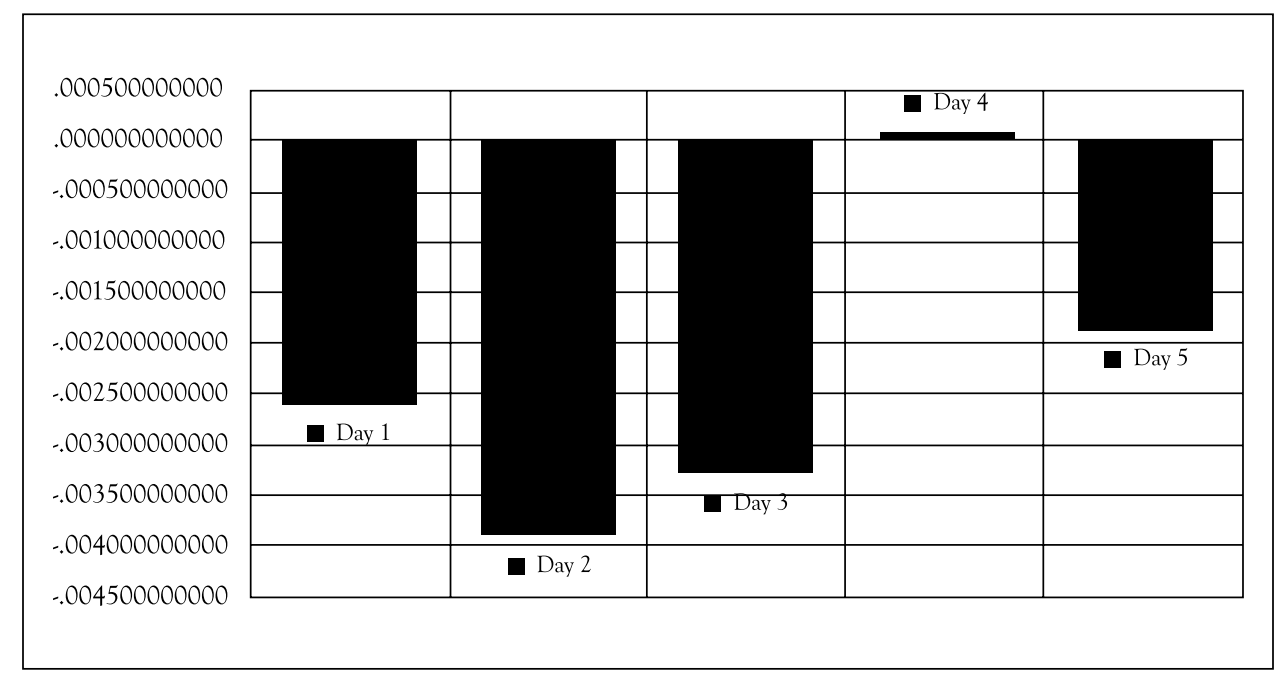

Figure 5: Mean Returns for Sat-Wed Sample

Table 5: Mean Stock Returns by Day of the Week for Trading Days from Saturday to Wednesday

\begin{tabular}{|c|c|c|c|c|c|c|}
\hline $\begin{array}{c}\text { Summary } \\
\text { Statistics }\end{array}$ & 1st Day & 2nd Day & 3rd Day & 4th Day & 5th Day & Cumulative \\
\hline Obs (n) & 25 & 22 & 23 & 24 & 22 & 116 \\
\hline MinVal & -0.028626 & -0.031934 & -0.014004 & -0.032073 & -0.03242 & -0.03242 \\
\hline MaxVal & 0.0298747 & 0.0255152 & 0.0306459 & 0.0301283 & 0.0210534 & 0.0306459 \\
\hline Mean & -0.002603 & -0.003893 & 0.0052589 & 0.000078 & -0.001860 & -0.0005936 \\
\hline t-stat & -1.010 & -1.417 & -0.443 & 0.256 & -0.641 & - \\
\hline DF & 24 & 21 & 22 & 23 & 21 & - \\
\hline p-value & 0.322 & 0.171 & 0.662 & 0.800 & 0.528 & - \\
\hline
\end{tabular}

Level of Significance/Decision Rule $(\alpha)=0.05$

Obs (n): Number of observations. MinVal: Minimum Value of the Daily KSE Returns. MaxVal: Maximum Value of the Daily KSE Returns. Mean: Average of the Daily Returns. t-test: $\mathrm{H}_{\mathrm{o}}$ states that the average daily log return of the investigated day is equal to the average daily log return of other weekdays.

While comparing with those of other trading days of week, the mean return of the second trading day has the lowest negative returns but the difference is insignificant as evident from the t-value. Based on its p-value of 0.171 which is larger than 0.05 , $\mathrm{H}_{\mathrm{o}}$ can not be rejected in this scenario. This implies that the average returns between second trading day and remaining trading days are not different statistically. The first trading day also shows lower return of -0.002603 , while its p-value is 0.322 , which is quite large as compared to $\triangle=0.05$; therefore we can conclude that average yield of 
first trading day is not significantly different in comarison with returns of remaining trading days; thus there is no first day effect as well. Overall the p-values of t-test are found to be insignificant; which show that the difference in mean returns between a specific day under observation and the other trading days is insignificant for the above sample and therefore no day of the week effect is present.

As shown in Figure 6, first trading day depicts the lowest negative mean returns which is followed by the second trading day. The fifth trading day as usual has the

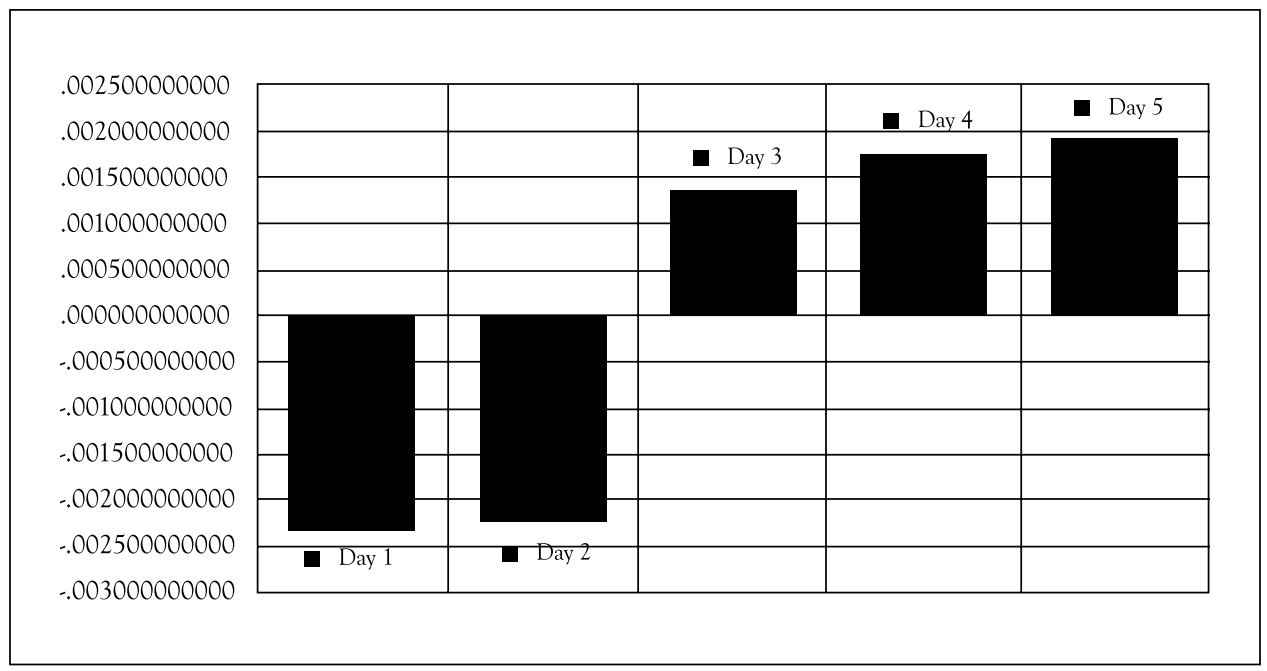

Figure 6: Mean Returns for Sun-Thu Sample

highest positive mean returns followed by the fourth and the third trading days respectively. Results of the t-test are presented in Table 6.

Table 6: Mean Stock Returns by Day of the Week for Trading Days from Sunday to Thursday

\begin{tabular}{|c|c|c|c|c|c|c|}
\hline $\begin{array}{c}\text { Summary } \\
\text { Statistics }\end{array}$ & 1st Day & 2nd Day & 3rd Day & 4th Day & 5th Day & Cumulative \\
\hline Obs (n) & 208 & 222 & 221 & 223 & 215 & 1089 \\
\hline MinVal & -0.055272 & -0.034293 & -0.041771 & -0.035168 & -0.040927 & -0.0552722 \\
\hline MaxVal & 0.0486891 & 0.0339831 & 0.0445279 & 0.052932 & 0.0426466 & 0.052932 \\
\hline Mean & -0.002311 & -0.002240 & 0.0013755 & 0.0017934 & 0.0019276 & 0.0001288 \\
\hline t-stat & $-3.258^{*}$ & $-3.916^{*}$ & 1.869 & $2.447^{*}$ & $2.703^{*}$ & - \\
\hline DF & 207 & 221 & 220 & 222 & 214 & - \\
\hline p-value & 0.001 & 0.000 & 0.063 & 0.015 & 0.007 & - \\
\hline
\end{tabular}

Level of Significance/Decision Rule $(\alpha)=0.05$ 
First trading day shows significantly lowest mean return at -0.002311 followed by the signifantly lowest on second trading day at -0.00224 , having p-values of 0.001 and 0.000 respectively. The mean returns of fourth and fifth trading days are also significantly different having p-values of 0.015 and 0.007 respectively, with fifth trading day as the highest positive mean return generator. The third trading day has insignificantly different mean return which is evident from its p-value above the threshold level. Therefore, the null hypothesis can be rejected in favor of first, second, fourth and fifth trading days, which indicates that the mean return on these days are significantly different from other days. Therefore, for this sample, there exists a negative first and second trading day effect and a positive fourth and fifth trading day effect, which is consistent with the findings of Cross (1973), Keim and Stambaugh (1984), and Chen et al. (2001).

Figure 7 indicates a usual lowest mean return for the first trading day, while the highest mean return is found to be on the third trading day followed by fifth, second and third trading days respectively. Results of the t-test are presented in Table 7.

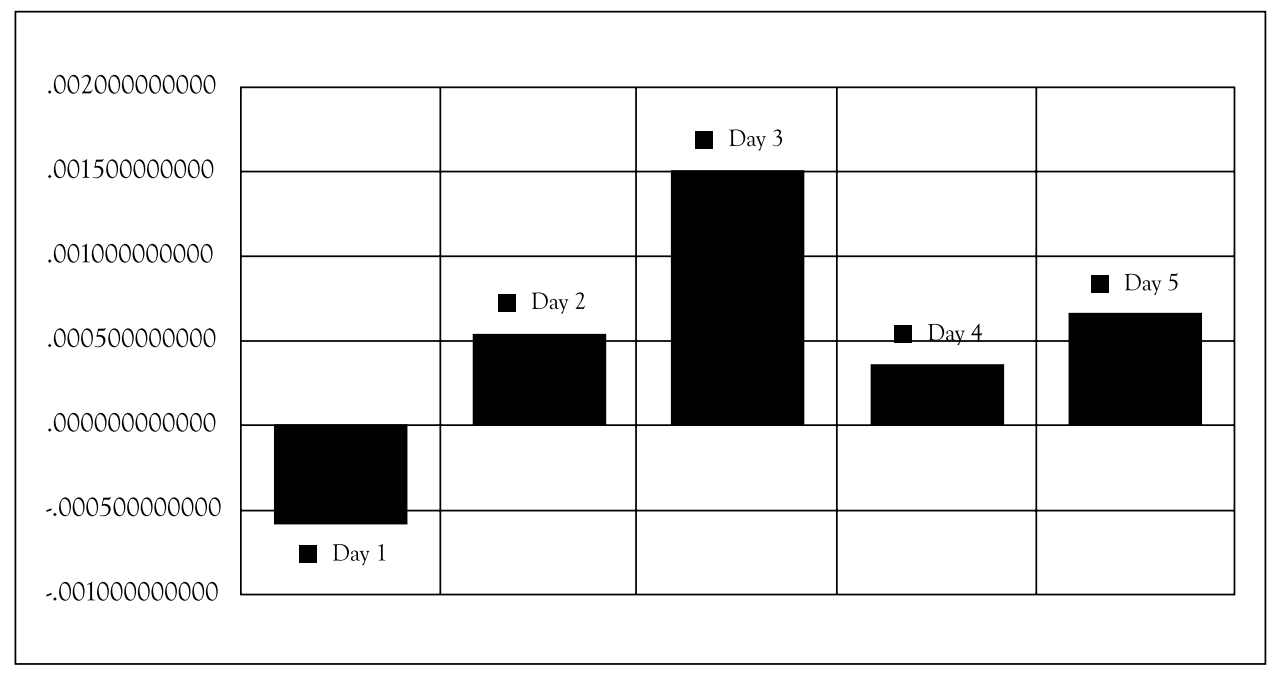

Figure 7: Mean Returns for Mon-Fri Sample

Table 7: Mean Stock Returns by Day of the Week for Trading Days from Monday to Friday

\begin{tabular}{|c|c|c|c|c|c|c|}
\hline $\begin{array}{c}\text { Summary } \\
\text { Statistics }\end{array}$ & 1st Day & 2nd Day & 3rd Day & 4th Day & 5th Day & Cumulative \\
\hline Obs (n) & 738 & 733 & 744 & 730 & 714 & 3659 \\
\hline MinVal & -0.132132 & -0.091453 & -0.067825 & -0.076448 & -0.089079 & -0.1321329 \\
\hline MaxVal & 0.074849 & 0.100029 & 0.1276223 & 0.0716412 & 0.0850712 & 0.1276223 \\
\hline
\end{tabular}




\begin{tabular}{|c|c|c|c|c|c|c|}
\hline Mean & -0.000581 & 0.000544 & 0.0015117 & 0.0003622 & 0.0006645 & 0.0005011 \\
\hline t-stat & -1.853 & 0.089 & $2.056^{*}$ & -0.314 & 0.339 & - \\
\hline DF & 737 & 732 & 743 & 729 & 713 & - \\
\hline p-value & 0.064 & 0.929 & 0.040 & 0.754 & 0.735 & - \\
\hline
\end{tabular}

Level of Significance/Decision Rule $(\alpha)=0.05$

Obs (n): Number of observations. MinVal: Minimum Value of the Daily KSE Returns. MaxVal: Maximum Value of the Daily KSE Returns. Mean: Average of the Daily Returns. t-test: $\mathrm{H}_{\mathrm{o}}$ states that the average daily log return of the investigated day is equal to the average daily log return of other weekdays.

First trading day shows an insignificant lowest mean return at -0.000581 while the third trading day shows a significantly high mean return at 0.0015117 as shown by their respective $t$-values. The p-value for third Day $(0.040)$ is less than 0.05 , therefore the $\mathrm{H}_{\mathrm{o}}$ can safely be rejected in this scenario, which depicts that average yield on the third day is significantly different as compared to returns of remaining trading days. Hence, for this sample there exists a Positive third trading day effect which is consistent with Guo and Wang (2007).

\subsection{Regression Results}

This section presents the regression results of DOW effect in sub-samples based on changing trading days (Table 8) and different political regimes (Table 9).

Table 8: Day of the week effect for Subsamples based on changing trading days

\begin{tabular}{|c|c|c|c|c|}
\hline Coefficients & Full & Sat-Wed & Sun-Thu & Mon-Fri \\
\hline$\alpha_{1}$ & $-0.001068(-1.86)$ & $-0.0026038(-1.14)$ & $-0.0023116(-2.5)^{*}$ & $-0.000581(-0.79)$ \\
\hline$\alpha_{2}$ & $0.0009824(1.32)$ & $-0.0012898(-0.44)$ & $0.0000714(0.07)$ & $0.001125(1.18)$ \\
\hline$\alpha_{3}$ & $0.0026347(3.48)^{*}$ & $0.0078627(2.41)^{*}$ & $0.0036871(3.21)^{*}$ & $0.0020927(2.16)^{*}$ \\
\hline$\alpha_{4}$ & $0.0017254(2.39)^{*}$ & $0.0026819(0.67)$ & $0.004105(3.35)^{*}$ & $0.0009432(1.04)$ \\
\hline$\alpha_{5}$ & $0.0020475(2.85)^{*}$ & $0.0007433(0.24)$ & $0.0042392(3.52)^{*}$ & $0.0012455(1.37)$ \\
\hline
\end{tabular}

The first column enlists the coefficients of the Dummy Variables under observation. The first Coefficient pertains to the dummy variable $D_{1}$ of the first day of the week and is represented by $\alpha_{1}$. The second Coefficient pertains to the dummy variable $D_{2}$ of the second day of the week and is represented by $\alpha_{2}$. The third Coefficient pertains to the dummy variable $D_{3}$ of the third day of the week and is represented by $\alpha_{3}$. The fourth Coefficient pertains to the dummy variable $D_{4}$ of the fourth day of the week and is represented by $\alpha_{4}$. The fifth Coefficient pertains to the dummy variable $D_{5}$ of the fifth day of the week and is represented by $\alpha_{5}$. The second column of the table provides values of the coefficients of dummy variables from first day of the week to the fifth day for the Full sample of study i.e from December 14, 1991 to Feb 18, 2013. The third column of the table provides values of the coefficients of dummy variables from first day of the week to the fifth day for the sub-sample from December 14, 1991 to June 06, 1992 where the trading days were from Saturday to Wednesday. The fourth column of the table provides values of the coefficients of dummy variables from first day of the week to the fifth day for the sub-sample from June 07, 1992 to February 27, 1997 where the trading days were from Sunday to Thursday. The fifth column of the table provides values of the coefficients of dummy variables from first day of the week to the fifth day for the sub-sample from 
February 28, 1997 to Feb 18, 2013 where the trading days were from Monday to Friday. The values in parenthesis under each coefficient's corresponding numeric value are the test statistics ( $t$-stat). The $t$-stats with a star in superscript depict a significant value.

Table 8 shows that the returns on third, fourth and last trading day of the week are significantly greater than 0 . The yields of other trading weekdays are significantly larger as compared to returns on first trading day. While the stock returns on the first trading day are found to be negative, they are, however insignificantly different from 0 . Thus the first trading day shows insignificant returns which denies the presence of first trading day effect.

During the subsample in which trading days were from Saturday to Wednesday, the returns on third trading day are significantly larger than 0 while the stock yields on first and second trading day are negative but insignificantly different from 0 . Returns on the fourth and fifth trading day are greater than zero but also insignificant.

In the Subsample with trading days from Sunday to Thursday, a significant first trading day effect is found with significant negative returns on the first day. The returns on second trading day are positive but insignificantly different from zero while the third, fourth and fifth trading day show significantly positive returns.

During the subsample with Monday to Friday trading days, the only significant positive return is found on the third trading day. The first trading day shows a negative return which is insignificantly different from zero. The second, third, fourth and fifth trading day depict positive but insignificant returns.

Table 9 shows the regression results of day of the week effect in different political regimes

Table 9: Day of the Week Effect in different Political Regimes

\begin{tabular}{|c|c|c|c|}
\hline Coefficients & PML-N Regime & PPP Regime & PML-Q Regime \\
\hline$\alpha_{1}$ & $-0.0011273(-0.75)$ & $-0.0022303(-3.08)^{*}$ & $0.0004085(0.44)$ \\
\hline$\alpha_{2}$ & $-0.0002994(-0.15)$ & $0.0021664(2.28)^{*}$ & $0.0001654(0.14)$ \\
\hline$\alpha_{3}$ & $0.0021658(1.03)$ & $0.0030919(3.32)^{*}$ & $0.0022246(1.9)$ \\
\hline$\alpha_{4}$ & $0.0009456(0.5)$ & $0.0028849(3.24)^{*}$ & $0.0007705(0.65)$ \\
\hline$\alpha_{5}$ & $0.0009069(0.49)$ & $0.0039765(4.5)^{*}$ & $0.0003822(0.32)$ \\
\hline
\end{tabular}

The first column enlists the coefficients of the Dummy Variables under observation. The first Coefficient pertains to the dummy variable D1 of the first day of the week and is represented by $\alpha 1$. The second Coefficient pertains to the dummy variable D2 of the second day of the week and is represented by $\alpha 2$. The third Coefficient pertains to the dummy variable D3 of the third day of the week and is represented by $\alpha 3$. The fourth Coefficient pertains to the dummy variable D4 of the fourth day of the week and is represented by $\alpha 4$. The fifth Coefficient pertains to the dummy variable D5 of the fifth day of the week and is represented by $\alpha 5$. The second column of the table provides 
values of the coefficients of dummy variables from first day of the week to the fifth day for the PML-N Regime. The third column of the table provides values of the coefficients of dummy variables from first day of the week to the fifth day for the PPP Regime. The fourth column of the table provides values of the coefficients of dummy variables from first day of the week to the fifth day for the PML-Q Regime. The values in parenthesis under each coefficient's corresponding numeric value are the test statistics (t-stat). The $t$-stats with a star in superscript depict a significant value.

During the regime of PML-N, returns on first and second trading day are negative but insignificantly different from 0 which indicates the absence of first and second trading day effect on returns. The returns for the remaining days are positive but insignificant. This implies the absence of any day of the week during the PML-N regime in consistence with findings of Ajayi et al. (2004) and Apolinario et al. (2006).

During the PPP regime, all days of the week depict significant return patterns. The first trading day shows significantly low negative returns. The second trading day through the fifth trading day all depict significantly positive returns with the highest positive returns on the fifth trading day. This indicates the existence of day of the week effect of all trading days for the PPP regime and is consistent with the existent body of literature as discussed in the previous section as well as in the literature review.

Finally, the regime of PML-Q depicts that there are insignificantly positive returns on the first trading day through the last trading day. However, the highest mean returns are found on the third trading day with a marginally insignificant $p$-value of 0.058 which is very close to being significant. Furthermore, there are no negative returns found during this period but all the returns are insignificant which indicates the absence of any day effect on the stock returns.

\section{Conclusion}

This study finds strong evidence of the existence of significant day of the week effect during the regime of Pakistan Peoples' Party (PPP) during all trading days. The Regimes of Pakistan Muslim League-N and Pakistan Muslim League-Q do not depict any existence of a significant day of the week effect. However the pattern of the day effect is found to be different from each other when compared. The pattern of day effect throughout the PPP regime is consistent with the traditionally studied pattern with negative first day returns and positive returns on the remaining trading days with highest returns being on the last trading day. The PML-N regime reflects a comparatively more efficient market when compared to the PPP regime as the day effect is not significantly discovered with traces of negative first and second day returns. Finally, the PML-Q regime does not depict any day effect with positive returns throughout the weekdays. Thus by comparison, the market during PML-Q regime stands out as the most efficient market of all three regimes.

Similar studies in the field of market anomalies and political regimes can be 
suggested to improve the estimation in the KSE. As a first suggestion, the indices prevalent in the KSE other than the KSE-100 can be positively utilized by means of similar methodology of this study. For example the KSE-30 index, the KSE All Share Index, the KSE Meezan Index - KMI 30 can be taken into consideration. It will result in a further understanding of the seasonal patterns present in these indices and will serve as a milestone to further understand the Pakistani capital market. Further, it is recommended for the upcoming researchers to use the same KSE-100 index and test it for the presence of other seasonal anomalies, like turn of the month effect, the yearly effect, holiday effect, Ramadhan effect, Christmas effect etc.

\section{References}

Abdallah, S. Z. (2012). Day-of-the-week effect on returns and conditional volatility: Empirical evidence from sudanese stock market. Middle Eastern Finance and Economics, 16(1), 167-180.

Ajayi, R. A., Mehdian, S., \& Perry, M. J. (2004). The day of the week effect in stock returns: Further evidence from Eastern European emerging markets. Emerging Markets Finance E Trade, 40(4), 53-62.

Akgiray, V. (1989). Conditional heteroscedasticity in time series of stock returns: Evidence and forecasts. The Journal of Business, 62(1), 55-80.

Alesina, A., \& Sachs, J. (1988). Political parties and the business cycle in the United States, 1948-1984. Journal of Money, Credit, and Banking, 20(1), 63-82.

Allvine, F. C., \& O’Neill, D. E. (1980). Stock market returns and the presidential election cycle: Implications for market efficiency. Financial Analysts Journal, 36(5), 49-56.

Apolinario, R. M., Santana, O. M., \& Sales, L. J. (2006). Day of the week effect on European stock markets. International Research Journal of Finance and Economics, 2(1), 53-70.

Barone, E. (1990). The Italian stock market: efficiency and calendar anomalies. Journal of Banking $\mathfrak{E}$ Finance, 14(2), 483-510.

Berument, H., \& Kiymaz, H. (2001). The day of the week effect on stock market volatility. Journal of Economics And Finance, 25(2), 181-193.

Bespalko, M. (2009). Bespalko, M. (2009). Calendar effects in daily bond returns: case of selected emerging economies (Doctoral dissertation, Kyiv School of Economics).

Board, J. L., \& Sutcliffe, C. M. (1988). The weekend effect in UK stock market returns.Journal of Business Finance E⿱ Accounting, 15(2), 199-213.

Cadsby, C. B. (1992). Turn of month and pre-holiday effects on stock returns: Some international evidence. Journal of Banking and Finance, 16(3), 497-509.

Chang, E. C., Pinegar, J. M., \& Ravichandran, R. (1993). International evidence on the robustness of 
the day of the week effect. Journal of Financial and Quantitative Analysis, 28(04), 497-513.

Chappel, H. W., \& Keech, W. R. (1986). Party differences in macroeconomic policies and outcomes. The American Economic Review, 76(2), 71-74.

Chen, G., Kwork, C. C., \& Rui, O. M. (2001). The day of the week regularity in the stock markets of China. Journal of Multinational Financial Management, 11(2), 139-163.

Chia, R. C.J., Liew, V. K.-S., Wafa, S. K., \& Wafa, S. A. (2006). Calendar anomalies in the Malaysian stock market. MPRA Paper No, 516. 1-27

Connolly, R. A. (1989). An examination of the robustness of the weekend effect. Journal of Financial and quantitative Analysis, 24(02), 133-169.

Cross, F. (1973). The behavior of stock prices on Fridays and Mondays. Financial Analysts Journal, 29(6), 67-69.

DeFusco, R. A., McCabe, G. M., \& Yook, K. C. (1993). Day of the week effects: A test of the information timing hypothesis. Journal of Business Finance $\mathcal{E}$ Accounting, 20(6), 835-842.

Demirer, R., \& Karan, M. B. (2002). An investigation of the day-of-the-week effect on stock returns in Turkey. Emerging Markets Finance $\mathcal{E}$ Trade, 38(6), 47-77.

Dicle, M. F., \& Hassan, K. M. (2006). Day of the week effect in Istanbul stock exchange. Scientific Journal of Administrative Development, 5.

Dubois, M., \& Louvet, P. (1996). The day-of-the-week effect: The international evidence. Journal of Banking $\mathcal{E}$ Finance, 20(9), 1463-1484.

French, K. R. (1980). Stock returns and the weekend effect. Journal of financial economics, 8(1), 55-69.

Gibbons, M. R., \& Hess, P. (1981). Day of the week effects and asset returns. The Journal of Business, 54(4), 579-596.

Gugten, V. D. (2010). Stock market calendar anomalies and macroeconomic news announcements. Erasmus University.

Guo, S. \& Wang, Z. (2007). Market Efficiency Anomalies: A study of seasonality effect on the Chinese Stock Exchange, Umeå, Sweden

Haroon, M. A., \& Shah, N. (2013). Investigating day-of-the-week effect in stock returns: Evidence from Karachi Stock Exchange - Pakistan. Pakistan Journal of Commerce and Social Sciences, 7(2), 381-393.

Hensel, C. R., \& Ziemba, W. T. (1995). United States investment returns during Democratic and Republican administrations, 1928-1993. Financial Analysts Journal, 51(2), 61-69.

Hussain, F. (1998). A Seasonality in the Pakistani equity market: The Ramadhan effect. The Pakistan Development Review, 37(1), 77-81. 
Hussain, F., \& Qasim, M. A. (1997). The Pakistani equity market in 50 years: a review. The Pakistan Development Review, 36(4), 863-872.

Hussain, F. (2000). The day of the week effect in the Pakistani equity market: An investigation. The Lahore Journal, 5(1), 93-98.

Hussain, F., Hamid, K., Akash, R. S., \& Khan, M. I. (2011). Day of the week effect and stock returns: Evidence from Karachi Stock Exchange, Pakistan. Far East Journal of Psychology and Business, 3(1), 25-31.

Jaffe, J., \& Westerfield, R. (1985, Jun). The weekend effect in common stock returns: The international evidence. The Journal of Finance, 40(2), 433-454.

Kansas, D. (1996). Researchers pore over blue-chip history. Wall Street Journal, C1-C2.

Ke, M.-C., Chiang, Y.-C., \& Liao, T. L. (2007). Day-of-the-week effect in the Taiwan foreign exchange market. Journal of Banking and Finance, 31(9), 2847-2865.

Keim, D. B., \& Stambaugh, R. F. (1984). A further investigation of the weekend effect in stock returns. The Journal of Finance, 39(3), 819-835.

Kiymaz, H., \& Berument, H. (2003). The day of the week effect on stock market volatility and volume: International evidence. Review of Financial Economics, 12(4), 363-380.

Lakonishok, J., \& Levi, M. (1982). Weekend effects on stock returns: A note. The Journal of Finance, 37(3), 883-889.

Lakonishok, J., \& Smidt, S. (1988). Are seasonal anomalies real? A ninety-year perspective. The Review of Financial Studies, 1(4), 403-425.

Liano, K., \& Gup, B. E. (1989). The day-of-the-week effect in stock returns over business cycles. Financial Analysts Journal, 45(4), 74-77.

Liano, K., Liano, K., \& Manakyan, H. (1999). Presidential administrations and the day-of-the-week effect in stock returns. Review of Financial Economics, 8(1), 93-99

Malkiel, B. G. (2003). The efficient market hypothesis and its critics. The Journal of Economic Perspectives, 17(1), 59-82.

Mazal, L. (2009). Stock Market Seasonality: Day of the Week Effect and January Effect.

Mitra, P., \& Khan, G. S. (2014). An Analysis of Day-Of-The-Week and Intraday Effects in the Indian Stock Market: Evidence from National Stock Exchange. Journal of Contemporary Issues in Business Research, 3(3), 115-127.

Neiderhoffer, V., Gibbs, S., \& Jim, B. (1970). Presidential elections and the stock market. Financial Analysts Journal, 26(2), 111-113.

Newey, W. K., \& West, K. D. (1987). Hypothesis testing with efficient method of moments estimation. International Economic Review, 28(3), 777-787. 
Nippani, S., \& Arize, A. C. (2007). U.S.corporate bond returns: A study of market anomalies based on broad industry groups. Review of Financial Economics, 17(3), 157-171.

Nishat, M., \& Mustafa, K. (2002). Anomalies in Karachi Stock Market: Day of the week effect. The Bangladesh Development Studies, 28(3), 55-64.

Polwitoon, S., \& Tawatnuntachai, O. (2008). Emerging market bond funds: A comprehensive analysis. The Financial Review, 43(1), 51-84.

Riley, W. B., \& Luksetick, W. A. (1980). The market prefers republicans: Myth or reality. The Journal of Financial and Quantitative Analysis, 15(03), 541-560.

Rogalski, R. J. (1984). New findings regarding day-of-the-week returns over trading and non-trading periods: A note. The Journal of Finance, 39(5), 1603-1614.

Siegel, Jeremy J (1994). Stocks for the long run: A guide to selecting markets for long-term growth. Irwin, Burr Ridge, III

Smirlock, M., \& Starks, L. (1986). Day-of-the-week and intraday effects in stock returns. Journal of Financial Economics, 17(1), 197-210.

Solnik, B. (1990). The distribution of daily stock returns and settlement procedures: The Paris Bourse. The Journal of Finance, 45(5), 1601-1609.

Solnik, B., \& Bousquet, L. (1990). Day-of-the-week effect on the Paris Bourse. Journal of Banking $\mathcal{E}$ Finance, 14(2), 461-468.

White, H. (1980). A heteroskedasticity-consistent covariance matrix estimator and a direct test for heteroskedasticity. Econometrica: Journal of the Econometric Society, 48(4), 817-838.

Wooldridge, J. (2006). Introductory econometrics : a modern approach (3rd ed). Thomson/South-Western, Mason, $\mathrm{OH}$.

Van Horne \& Wachowicz, John Martin (2008). Fundamentals of Financial Management (13 ${ }^{\text {th }}$ ed.). Harlow, England: Prentice Hall 
